\title{
CORRESPONDENCE
}

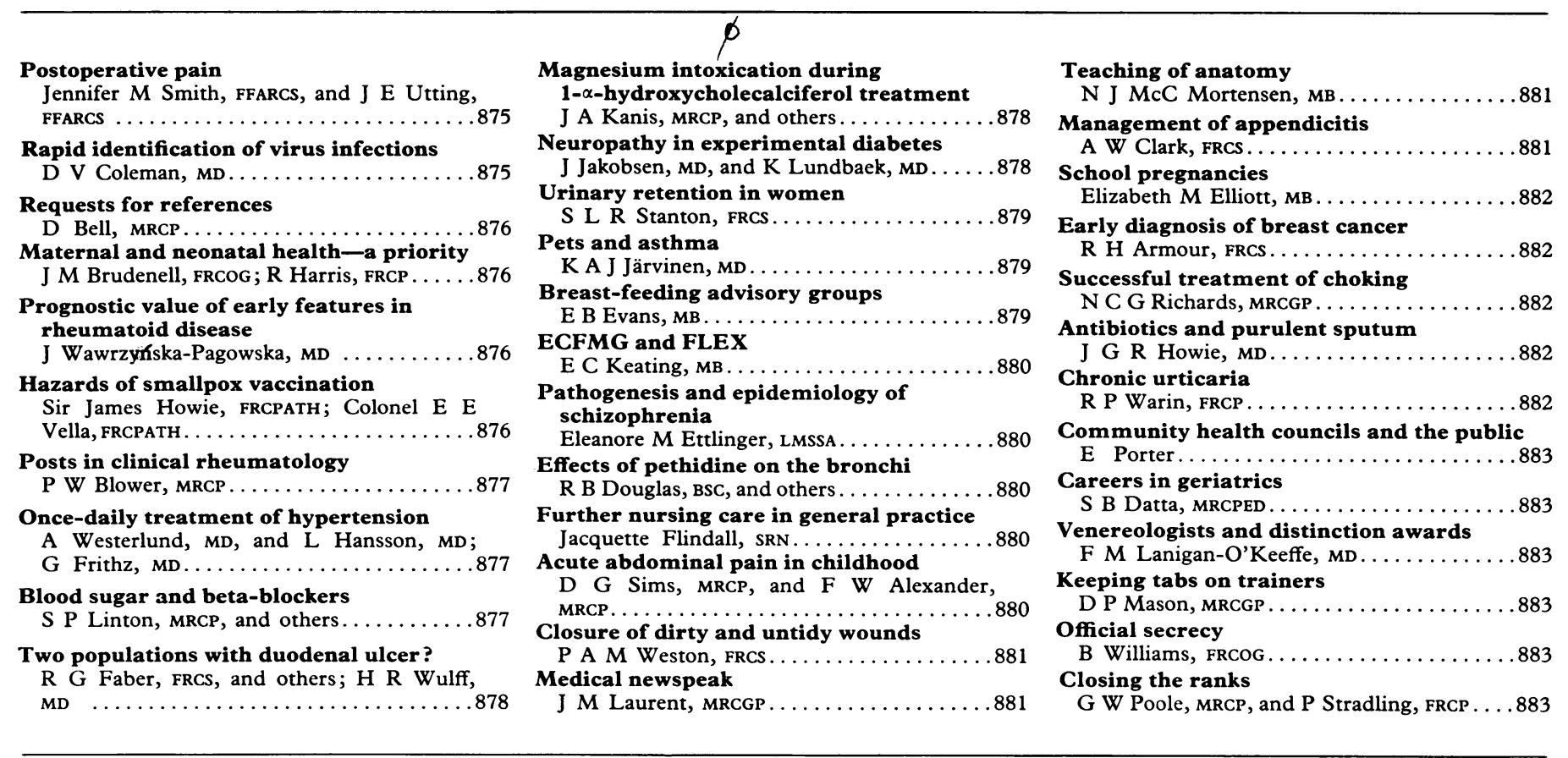

Correspondents are urged to write briefly so that readers may be offered as wide a selection of letters as possible. So many are being received that the omission of some is inevitable. Letters should be signed personally by all their authors.

\section{Postoperative pain}

SIR,-Your leading article on this neglected subject (18 September, p 664) is welcome, but there are a number of further points requiring emphasis. Though almost self-evident already, these points became even more obvious in the course of a study of postoperative analgesia with drugs which we hope shortly to publish. This involved questioning patients about pain after upper abdominal surgery and, later, questioning nursing staff who had been, of course, unaware that their administration of analgesic drugs was being scrutinised.

When a questionnaire was administered to patients on the first postoperative day over half put their pain in the most severe category available ("very unpleasant indeed; I would be very unhappy if I had to go through this again"). Yet no patient received all the doses of analgesic drug which should have been available according to the prescription-and usually the number given fell far short of this. As might be expected, the prescribing of the drugs seemed generally to be at once casual and over-cautious; the most common prescription was for "morphine $10 \mathrm{mg}$ up to fourhourly" and this seemed to be considered suitable for almost everybody.

Most patients denied that they were frightened to ask for a dose of analgesic drug but for various reasons they seldom did so; they appeared to think that if they should have it they would get it. In practice, anyway, the number of doses of analgesic administered to those who said that they were not afraid to ask for drugs was the same as the number given to those who said that they were.
Contrary to the suggestion in your article, nurses were not unduly worried about addiction or hypotension after analgesic drugs. They all said that they would give a dose of analgesic to a patient who seemed to be in pain if it was allowed by the prescription. The poor performance in practice may well be due in part to an inability to recognise that a patient is in severe pain when the traditional attitude is to try to conceal pain and keep a "stiff upper lip." Administrative factors, however, are also at work as is shown by the fact that the time at which the greatest number of doses of analgesic drugs was administered clearly depended on the nursing routine.

The drug treatment of postoperative pain is fundamentally unsatisfactory with the drugs at present available; any improvement is likely only to be marginal. The hope would seem to be that the subject will be given more prominence in the education of both doctors and nurses. Patients, too, should be told that asking for an analgesic drug is not necessarily a sign of frank cowardice.

Department of Anaesthesia

J M SMITH J E UTring University of Liverpool

\section{Rapid identification of virus infections}

SIR,-I read with interest your leading article (11 September, p 601) on this subject and would like to draw your attention to a quick, simple, and accurate laboratory method of detecting virus infections which was omitted from the article.

It is now routine for cytology screeners to be trained to recognise the cytopathic effect of herpes simplex virus in Papanicolaoustained cervical smears sent to routine cytological investigation for malignant cells, and as a result the cytopathologist is able to provide the clinician with information regarding the presence of genital infection with herpes simplex in his patient. In many laboratories cytological specimens are screened and reported on within $24 \mathrm{~h}$, thus facilitating confirmation of the cytodiagnosis by conventional virological methods while the patient is in the acute stages of the infection.

At this hospital a cytological diagnosis of genital herpes was made in 330 cervical smears $(5 \cdot 3 \%)$ from women attending the venereal disease clinic in 1975 and in just over half these cases $(55.5 \%)$ virus infection was clinically unsuspected when the smear was taken. These observations carry a special significance for, if the association between genital herpes and cervical cancer proves to be other than fortuitous, these patients represent a high-risk group. This extension of the cytological technique is particularly important for the correct management of women attending gynaecological outpatient, family planning, and well-women clinics who are not investigated routinely for venereal disease. The association between genital herpes and gonorrhoea is well documented and a cytodiagnosis of genital herpes in these women should indicate to the clinician the need for bacteriological and serological tests. While these cases are few in number $(37$ or $0.25 \%$ of smears from these sources in 1975), they appear to be increasing.

The application of the cytological technique to the detection of human polyomavirus infection in patients receiving cytotoxic drug 
therapy ${ }^{1}$ permits a preliminary cytodiagnosis to be made based on cytological examination of the urine sediment which can be confirmed by virus isolation and electron microscopy; and while the cytodiagnostic technique may not be the most sensitive way of detecting this new virus, it is certainly the simplest. In addition, the cytological technique is employed in the diagnosis of acute conjunctivitis due to trachoma agents. The characteristic inclusion bodies are identified in Giemsa-stained conjunctival smears. We also find we can recognise syncitia of conjunctival cells due to herpes simplex and herpes zoster infection in smears of the conjunctiva and cornea.

The simplicity of the cytodiagnosis technique and the rapidity with which a cytodiagnosis can be made from a smear makes it an appropriate method for screening. Although the sensitivity and the specificity of the cytological method do not approach that of conventional virological techniques, it is a method of detecting virus infections which might otherwise be overlooked. It is a method of supporting the clinical diagnosis when the special facilities of a virology laboratory are no to hand and it is a service which can be offered by every pathology department which has a cytology laboratory that is prepared to provide a comprehensive diagnostic service.

D V Coleman

Department of Experimental
Pathology,
St Mary's Hospital Medical School,
London W2

${ }^{1}$ Coleman, D V, Acta Cytologica, 1975, 19, 93.

\section{Requests for references}

SIR,-I was interested to read the letter from Mr P J E Wilson and Mr J S Waters (25 September, $p$ 752). I note that they have received a letter from an employing authority relating, inter alia, to the Rehabilitation of Offenders Act 1974 and a related Order 1975 and quoting part of the letter verbatim.

It has been drawn to my attention recently that applicants for posts are receiving a similar, though not identical, form of words. In view of the differences, may I quote the paragraph received by intending applicants?

"Because of the nature of the work for which you are applying, this post is exempt from the provisions of Section $4(2)$ of the Rehabilitation of Offenders Act 1974 by virtue of the Rehabilitation of Offenders Act 1974 (Exemptions) Order 1975 Applicants are, therefore, not entitled to withhold information about convictions which for other purposes are 'spent' under the provisions of the Act, and, in the event of employment, any failure to disclose such convictions could result in dismissal or disciplinary action by the Authority. Any information given will be completely confidential and will be considered only in relation to an application for positions to which the Order applies."

It seems to me unfair for authorities to send this out, either to referees or to applicants, without making available the relevant section of the Act and the Order and also without quoting the authority by which it is issued. If this was done it might answer a number of points. Are "convictions" limited to those resulting in custodial sentences? Do such "convictions" relate to actions brought only in the UK, or in the EEC, or in countries outside the EEC? If convictions relate to custodial sentences, does this include Borstal training or only sentences in HM prisons?
Finally, the implementation of this by employing authorities seems to me to introduce a degree of arbitrary control which is highly undesirable-is there, for instance, any appea against "disciplinary action"? In short, it fundamentally undermines the authority of the statutory body, the General Medical Council. I imagine that other, similar professional bodies must be viewing this development with grave misgivings.

Edinburgh

DAvid Beli

Maternal and neonatal health-a priority

SIR,-Professor R W Beard's plea on behalf of the maternity services in Britain (18 September, $p$ 679) demands the widest possible support from all obstetricians. However, it is clear that in future less money will be available to all branches of the NHS, and the maternity services must bear some share of the burden. It follows that if perinatal mortality and morbidity, the quality of the maternity services' product, are to be improved more efficient use must be made of present resources.

Economies can be made and obstetricians must now take a lead in examining the means. The variation in length of stay after delivery in different parts of the country suggests that earlier discharge of maternity patients could bring about worthwhile savings, but only if wards are closed as a result. Then again, the need to get value for money is as important in clinical as in commercial practice and obstetricians should view the investigations they order and the drugs they use, for example, in this light. All too often doctors have little or no idea of the monetary cost of the resources they employ, and the "best buy" approach, especially in relation to new and expensive equipment, though obvious, is not employed.

The key to successful savings is incentive. District management teams must be quick to reward economies made by individual maternity departments by returning a proportion of the money saved for improving departmental facilities. Money "earned" by a department in this way is likely to be wisely spent. The best incentive of all would be for every maternity department to control its own budget and be responsible for providing the best possible service for the price. And let no one forget that high standards in the maternity services mean healthy babies fit to build a prosperous Britain in the future.

M BRUdenelL

King's College Hospital.

London SE5

SIR,-I read with great interest Professor $\mathrm{R} \mathrm{W}$ Beard's comments (18 September, p 679) on what he would say to the Royal Commission concerned with "the best use and management of the financial and manpower resources of the National Health Services." One must sympathise with him when he contemplates the negative growth of the maternity services of the future in Britain.

Professor Beard's cogent plea for more consideration for the next generation as well as for current sufferers from handicap and for geriatric problems is timely. I would also emphasise that we might be looking more carefully at the earlier weeks of pregnancy. The prenatal diagnosis and abortion of two of the commonest causes of mental and physical handicap, mongolism and spina bifida, are producing a quiet revolution in the management of birth defect. Obstetricians working closely with their colleagues in clinical genetics might well find themselves favoured by the Royal Commission.

University Department of

RODNEY HARRIS

Medical Genetics,

St Mary's Hospital,
Manchester

Prognostic value of early features in rheumatoid disease

SIR,-In the excellent article by Dr A Fleming and others (22 May, p 1243) there is a significant mistake in the quotation from our paper. ${ }^{1}$

Among the 202 pre-erosive cases that we observed there were 102 persons, not 30, who had had the disease for under a year. At present our population of patients with the features of early rheumatoid arthritis observed for at least two years numbers 411 , and 120 have been observed for 10 years. Our results are to be published soon.

We are glad that the findings of Dr Fleming and his colleagues on early features indicating prognosis in rheumatoid arthritis are in entire agreement with our long-term observations.

J WAWRZYŃSKa-PAGOWSKa Institute of Rheumatology,

Warsaw, Poland Wawrzy rska-Pagowska, J, et al, Acta Rheumatologica
Scandinavica, 1970, 16, 99.

\section{Hazards of smallpox vaccination}

SIR,-Mr G T Watts's reply (2 October, p 813) to Dr F Kellerman (11 September, $\mathrm{p}$ 638) prompts me to emphasise how thoroughly the World Health Organisation (WHO) searches for cases of smallpox in a country both before and after it is declared free from the disease. Two years ago I saw the actions taken in Indonesia and was impressed by the rigorous and extremely competent clinical and laboratory checks carried out on any patient suffering from any disease that might be smallpox. Indonesia was and has remained free from smallpox. Four weeks ago I talked to a microbiologist recently returned from India who confirmed that exactly the same assurances could be given about WHO's search for possible cases in that country. Moreover, financial rewards of real value (about three months' salary for some) were offered to anyone reporting a case that turned out to be smallpox.

So I think that assurances may be given about the safety of our policy of abandoning infant vaccination against smallpox. Rules regarding vaccination of travellers ought to be cancelled forthwith; and I imagine that governments have enough confidence in WHO's evidence to ensure that this will be done without much delay.

\section{JAMES HowIE}

Newtonmore,

Inverness-shir

SIR,-Further to the correspondence on this subject (11 September, p 638; 2 October, p 813) another way out, between the pros and the contras on this theme, which is attractive to 